\title{
PRÁTICA PEDAGÓGICA COM HORTA ESCOLAR NO ENSINO DE CIÊNCIAS E BIOLOGIA
}

\section{Adriano Barbosa Almeida ${ }^{1^{*}}{ }^{(0)}$; Aline Barbosa Almeida ${ }^{\circledR}$; Gilivã Antonio Fridrich ${ }^{3}$}

\section{Resumo}

O espaço escolar tem se mostrado fundamental na formação indivíduos responsáveis e preparados para responder questões socioambientais. Neste contexto, a Educação Ambiental aliada a práticas pedagógicas despertam conceitos que promovem mudanças de atitudes e possibilitam a vivência na sustentabilidade nos mais variados ecossistemas A Educação ambiental é a mais eficiente forma de intervenção na ruptura com a vivência insustentável e na busca da preservação ambiental. 0 uso da horta escolar para o Ensino de Ciência e Biologia contribui para a prática de saberes essenciais, que oportunizam na formação individual e coletiva para reflexão e construção de atitudes responsáveis com o meio ambiente. Sendo assim, este estudo traz análise bibliográfica sobre a utilização da horta escolar como prática de ensino em Biologia e Ciências nas aulas de Educação Ambiental. Foram investigados trabalhos acadêmicos das plataformas Google Acadêmico, SCIELO e Periódicos da Capes. O método utilizado foi a Análise Textual Discursiva, com unitarização, categorização e construção de metatexto: "Meio ambiente e Escola: uma horta escolar para o Ensino de Ciências da Natureza e Biologia". Concluiu-se que a prática com horta contribui de maneira eficiente para aprendizagens significativas, dinâmicas e contextualizadas com os conteúdos das disciplinas em estudo. Assim como, espaços relevantes para práticas pedagógicas sustentáveis e com diferentes possibilidades dentro do ambiente escolar.

Palavras-chave: Horta Escolar. Metodologia. Ensino. Ciências da Natureza.

\section{Abstract}

The school space has proven to be fundamental in training responsible individuals who are prepared to respond to social and environmental issues. In this context, Environmental Education combined with pedagogical practices awaken concepts that promote changes in attitudes and enable the experience of sustainability in the most varied ecosystems. Environmental education is the most efficient form of intervention in breaking with unsustainable living and in the search for environmental preservation. The use of the school garden for teaching Science and Biology contributes to the practice of essential knowledge, which provide opportunities for individual and collective training for reflection and construction of responsible attitudes towards the environment. Therefore, this study brings bibliographical analysis on the use of the school garden as a teaching practice in Biology and Sciences in Environmental Education classes. Academic works from the Google Academic, SCIELO and Capes Periodicals platforms were investigated. The method used was Discursive Textual Analysis, with unitarization, categorization and metatext construction: "Environment and School: a school garden for the Teaching of Natural Sciences and Biology". It was concluded that the practice with the vegetable garden
1 Especialização em Educação Ambiental Interdisciplinar. Graduação em Ciências Biológicas

*adrianobpax@hotmail.com

2 Especialização em Educação Contemporaneidade e Novas Tecnologias. Graduação em Ciências Biológicas alinebshalom@gmail.com

3 Doutor em Desenvolvimento e Meio Ambiente. Mestre em Saúde e Meio Ambiente. Graduação em Ciências Biológicas. profgilivan@gmail.com efficiently contributes to meaningful, dynamic and contextualized learning with the contents of the subjects under study. As well as relevant spaces for sustainable pedagogical practices and with different possibilities within the school environment.

Keywords: School Garden. Methodology, Teaching, Natural Sciences
Recebido em: 10 Oct. 2021

Aceito em: 25 Nov. 2021

Publicado em: 30 Dez. 2021

(c) Copyright 2021

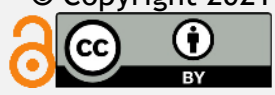

Almeida, A. B.; Almeida. A. B.; Fridrich, G. A. 


\section{Resumen}

El espacio escolar ha demostrado ser fundamental en la formación de personas responsables y preparadas para responder a los problemas sociales y ambientales. En este contexto, la Educación Ambiental combinada con las prácticas pedagógicas despiertan conceptos que promueven cambios de actitudes y posibilitan la vivencia de la sustentabilidad en los más variados ecosistemas. La educación ambiental es la forma de intervención más eficiente para romper con la vida insostenible y en la búsqueda de la preservación ambiental. . El uso del huerto escolar para la enseñanza de Ciencias y Biología contribuye a la práctica de conocimientos esenciales, que brindan oportunidades de formación individual y colectiva para la reflexión y construcción de actitudes responsables hacia el medio ambiente. Por tanto, este estudio trae un análisis bibliográfico sobre el uso del huerto escolar como práctica docente en Biología y Ciencias en las clases de Educación Ambiental. Se investigaron trabajos académicos de las plataformas Google Academic, SCIELO y Capes Periodicals. El método utilizado fue el Análisis Textual Discursivo, con unitarización, categorización y construcción de metatexto: "Ambiente y Escuela: un huerto escolar para la Enseñanza de las Ciencias Naturales y Biología". Se concluyó que la práctica con la huerta contribuye de manera eficiente a un aprendizaje significativo, dinámico y contextualizado con los contenidos de las materias objeto de estudio. Así como espacios relevantes para prácticas docentes sostenibles y con diferentes posibilidades dentro del entorno escolar.

Palabras-chave: Huerto escolar. Metodología. Enseñando. Ciéncias de la naturaleza. 


\section{Introdução}

$\mathrm{N}$ A escola tem se mostrado fundamental na formação indivíduos responsáveis e preparados para responder questões socioambientais. Neste contexto, a Educação Ambiental aliada a práticas pedagógicas desperta conceitos que promovem mudanças de atitudes e possibilitam a vivência na sustentabilidade nos mais variados ecossistemas (GUARIM, 2002).

Como contribuinte a esse processo educacional, 0 Ensino de Ciências e Biologia por muito tempo esteve restrito ao professor como detentor do saber e o aluno apenas como um receptor passivo (MARINHO et al., 2012). A qualidade da prática pedagógica estava ligada a quantidade de conteúdo ministrado, trazendo sérias consequências, como a não formação alunos pesquisadores, críticos e limitados a decorar conteúdos e regras (NUNES, et al., 2010).

Para ruptura com essa forma de ensino os professores sãos essenciais, ao propor situações e condições que direcionam os educandos ao desenvolvimento de competências e habilidades, os tornando capazes de analisar e criticar a sua realidade local e perceber a necessidade de preservação ambiental (AGUIAR, et al., 2017).

Neste sentido, o uso da horta escolar como recurso didático colabora ao ensino como algo próximo do aluno e do seu cotidiano, com aulas dinamizadas, prazerosas e com metodologias ativas (SILVA et al., 2007; SALGADO, PERES, 2010). Promove também o desenvolvimento de valores sociais, como: participação, melhor relação interpessoal e responsabilidade com questões ambientais (PEREIRA, et al, 2012).

Cabe destacar que o uso desta ferramenta pedagógica proporciona trabalhar temas transversais como meio ambiente, saúde, trabalho, consumo com uma abordagem interdisciplinar e atividades práticas atraentes a toda comunidade escolar (FROES et al., 2015). É um meio de transformar a sala de aula em um ambiente vivo, com novas aprendizagens e inclusão social, promovendo uma educação de qualidade e integral, com novas descobertas e múltiplas aprendizagens e competências (BANDEIRA, 2013).
Este estudo traz uma análise bibliográfica sobre a utilização da horta escolar como prática de ensino em Biologia e Ciências nas aulas de Educação ambiental e tem como propósito entender como é abordada a temática e sua contribuição na construção de valores ambientais para da vivência na sustentabilidade.

\section{MATERIAL E MÉTODOS}

A pesquisa faz uma revisão de literatura sobre o uso da horta escolar no Ensino de Ciências e Biologia. A coletada de dados foi realizada a partir das plataformas Google Acadêmico, SCIELO e Periódicos da Capes, utilizando a ferramenta de busca das respectivas plataformas foram inseridos os termos: horta escolar, metodologia, Ensino, Ciências e Biologia, para período de 2010 a 2020.

Utilizou-se como metodologia da Análise Textual Discursiva (MORAES, GALIAZZI, 2011), unitarização, categorização e construção de metatexto. Os trabalhos foram avaliados a partir de seus títulos, palavras-chaves e resumos e separados em partes relevantes, com foco na abordagem horta escolar. A unitarização aconteceu separando fragmentos de unidades significativas, e em seguida dada uma palavra-chave central a unidade, com agrupamento das unidades com significado parecidos que foi a categorização. Este processo contribuiu para construir as reflexões compõem o metatexto "Meio ambiente e Escola: uma horta escolar para o Ensino de Ciências da Natureza e Biologia”.

\section{RESULTADOS E DISCUSSÃO}

Foram selecionados dez trabalhosos quais serviram para análise desta pesquisa.

A Educação Ambiental através da metodologia de horta escolar no Ensino de Ciência e Biologia é um meio para a formação de alunos com potencial histórico, político e social, apto a mudar comportamentos para a vivência da sustentabilidade. Por meio dessa ferramenta de apoio pedagógico é possível tornar o ambiente escolar mais alegre e dinâmico, com o protagonismo do aluno na escolha do local, construção dos canteiros, seleção das hortaliças, preparação do adubo, plantio de mudas e sementes e os tratos 
culturais específicos de cada hortaliça (BANDEIRA, 2013).

A implantação da horta escolar é uma atividade extracurricular e depende principalmente do interesse do professor em desenvolver esta proposta interdisciplinar que pode integrar o Projeto Político Pedagógico (PPP) e muito contribuir para o desenvolvimento de metodologias ativas na escola e caracterização do currículo institucional da entidade. Segundo Moran (2018), as metodologias ativas promovem o protagonismo do aluno ao propor o envolvimento e reflexão em todo seu processo formativo, e tendo o professor dando apoio como orientador de todas as etapas da metodologia.

Os Parâmetros Curriculares Nacionais, (PCNs) estabelecem que:

A interdisciplinaridade supõe um eixo integrador, que pode ser o objeto de conhecimento, um projeto de investigação, um plano de intervenção. Nesse sentido, ela deve partir da necessidade sentida pelas escolas, professores e alunos de explicar, compreender, intervir, mudar, prever, algo que desafia uma disciplina isolada e atrai a atenção de mais de um olhar, talvez vários (BRASIL, 2002, p. 88-89).

De acordo com o PCN (1997), o ensino com horta favorece na observação das diversificadas maneiras de organização dos seres vivos, suas dinâmicas, transformações e perpetuação, bem como todo processo de renovação e reciclagem dos materiais.

A seguir (Tabela 1), são destacados trabalhos realizados em distintas regiões brasileiras, com relatos de práticas pedagógicas no Ensino de Biologia e Ciências. Identificados por T.1, T.2, ..., T.10, os quais foram analisados e discutidos e ajudam na construção do metatexto: Meio ambiente e Escola: uma horta escolar para o Ensino de Ciências da Natureza e Biologia.

Tabela 01: Trabalhos que compõem a análise qualitativa

\begin{tabular}{|c|l|}
\hline T.1 & $\begin{array}{l}\text { MELO, J. S. Horta escolar, cultivar é educar. Revista } \\
\text { Insignare. V.2, n. 1, ano 2019. } \\
\text { Disponível em: } \\
\text { https://periodicos.uffs.edu.br/index.php/RIS/artic } \\
\text { le/view/10776.Acesso em: 15 mar.2020. }\end{array}$ \\
\hline \multirow{1}{*}{ T.2 } & $\begin{array}{l}\text { SANTOS, E. C.; MOURA, N. A.; SANTOS, A. A. C.; } \\
\text { JÚNIOR, A. M. Horta Escolar: possibilidades } \\
\text { pedagógicas para o Ensino de Ciências. } \\
\text { In: CONGRESSO NACIONAL DE ENSINO DE CIÊNCIAS E }\end{array}$ \\
$\begin{array}{l}\text { FORMAÇÃO DE PROFESSORES, 2., 2019, Catalão. } \\
\text { Anais eletrônicos [...] Catalão: UFCAT, 2019. }\end{array}$ \\
\hline
\end{tabular}

\begin{tabular}{|c|c|}
\hline & $\begin{array}{l}\text { Disponível em: } \\
\text { http://cecifop.sistemasph.com.br/index. } \\
\text { php/cecifop/CECIFOP2019/paper/download/267/5 } \\
\text { 50. Acesso em: } 15 \text { mar.2020. }\end{array}$ \\
\hline T.3 & $\begin{array}{l}\text { SILVA, C.T.A. C.; MUNARETTO F. C.; MANTOVANI } \\
\text { T. Viabilidade da utilização da horta da escola como } \\
\text { laboratório para Ensino de Ciências e Biologia. } \\
\text { Revista Didática Sistêmica, v. 13, n. 1, } 2011 . \\
\text { Disponível } \\
\text { https://periodicos.furg.br/redsis/article/view/200 } \\
\text { 2. Acesso em: } 28 \text { fev. } 2020 \text {. }\end{array}$ \\
\hline T.4 & $\begin{array}{l}\text { BENITES, M.; PEREIRA, Z. V.; SANGALLI, A.; } \\
\text { FERNANDES, S. S. L., LIMA, C. T. N. Ensino de } \\
\text { Ciências através da prática agrícola - a horta na } \\
\text { escola indígena da aldeia Pirajuí, município de } \\
\text { Paranhos, MS. Revista Online de Extensão da } \\
\text { UFGD. v.1, n. 2,2014. } \\
\text { Disponível em: } \\
\text { http://ojs.ufgd.edu.br/index.php/realizacao/anno } \\
\text { uncement. Acesso em: } 17 \text { fev. } 2020 \text {. }\end{array}$ \\
\hline T.5 & $\begin{array}{l}\text { RODRIGUES, M. D.; CIPRIANO, D. M.; ESTEVAM, B.S.; } \\
\text { CALHEIROS, D.L. M.; NETO, F. Q.V.; LEITÃO, A.S. } \\
\text { L.A educação ambiental através da horta escolar: } \\
\text { um estudo de caso entre duas escolas da cidade de } \\
\text { Rio Grande/RS. Revista Tempos e espaços em } \\
\text { Educação. v. } 11 \text {, n. } 27,2018 \text {. } \\
\text { Disponível em: } \\
\text { https://seer.ufs.br/index.php/revtee/article/view } \\
\text { /7272.Acesso em: } 22 \text { jun. } 2020 \text {. }\end{array}$ \\
\hline T.6 & $\begin{array}{l}\text { NUNES, P. S. Hortas para a promoção de saberes } \\
\text { sobre alimentação saudável e Ensino de Ciências } \\
\text { para alunos com necessidades educacionais } \\
\text { especiais. Revista Espaço Acadêmico. v. 15, n. 177, } \\
2016 \text {. } \\
\text { Disponível em: } \\
\text { http://www.periodicos.uem.br/ojs/index. } \\
\text { php/EspacoAcademico/article/view/30659. Acesso } \\
\text { em: } 22 \text { jun. } 2020 \text {. }\end{array}$ \\
\hline T.7 & $\begin{array}{l}\text { SOUZA, R.; SANTOS, G. M. M. AGUIAR, W. M. } \\
\text { CHAVES, J. } \\
\text { Horta escolar e suas múltiplas possibilidades em } \\
\text { Salvador - Bahia. In: Seminário Nacional de } \\
\text { Integração da rede PROFCIAMB, 3. 2018, Belém. } \\
\text { Anais [...]. Belém. PROFCIAMB. 2018. } \\
\text { Disponível em: http://geciamb.eesc.usp.br/index. } \\
\text { php/ufpaprofciamb/ufpaprofciamb/paper/view/71 } \\
\text { 6. Acesso em: } 22 \text { jun. 2020. }\end{array}$ \\
\hline T.8 & $\begin{array}{l}\text { SILVEIRA, F., J.; RIOS, S., A. A horta escolar como } \\
\text { laboratório vivo no ensino de ciências In: CONGRESO } \\
\text { BRASILEIRO DE AGROECOLOGIA, 4.,2015.Belém. } \\
\text { Anais [...]. Belém. Revista Cadernos de } \\
\text { Agroecologia. } 2015 . \\
\text { Disponível em: } \\
\text { http://revistas.abaagroecologia.org.br/index.php/ } \\
\text { cad/article/view/17159.Acesso em: } 05 \text { jun. } 2020 \text {. }\end{array}$ \\
\hline Т.9 & $\begin{array}{l}\text { OLIVEIRA, D.A. A. S. MESSEDER, J. C. M. Horta } \\
\text { escolar como estratégia de ensino: possibilidades } \\
\text { para discussões sociocientíficas diante do } \\
\text { protagonismo infantil. In: Simpósio Nacional de } \\
\text { Ciência, Tecnologia e Sociedade, 7.,2017, Brasília. } \\
\text { Anais [...] Brasília: ESOCITE. BR, 2017. } \\
\text { Disponível } \\
\text { https://esocite2017.com.br/site/anais- } \\
\text { eletronicos. Acesso em: } 16 \text { jan. } 2020 .\end{array}$ \\
\hline
\end{tabular}




\begin{tabular}{|l|l|}
\hline \multirow{5}{*}{ T.10 } & SIQUEIRA, F. M. B.; AMORIM, F. D. A. S. A. SOUZA, \\
F.S. C.; SILVA, A. C. V.; MARTINS, M. E. P. Horta \\
escolar como ferramenta de educação ambiental \\
em uma escola estadual no município de Várzea \\
Grande - MT. In: Congresso Brasileiro de Gestão \\
Ambiental, 7, 2016, Campina Grande. Anais [...] \\
Campina Grande: IBEAS, 2016. Disponível em: \\
https://periodicos.unifesp.br/index.php/revbea/a \\
rticle/download/2546/1584/Acesso em: 03 jan. \\
2020.
\end{tabular}

Meio ambiente e Escola: uma horta escolar para o Ensino de Ciências da Natureza e Biologia

0 uso da horta escolar contribui para o desenvolvimento de práticas que favorecem em múltiplas aprendizagens, promovendo nas aulas maior interação como $o$ meio ambiente $e$ consequentemente maior sensibilização aos impactos ambientais. Neste sentido, o Melo (2019, p.121), destaca o estudo do o solo e sua vivência de forma sustentável:

[...] foco foi constatar a qualidade do solo de uma horta escolar que será utilizado como espaço pedagógico, para aprendizagens dos alunos de como produzir hortaliças saudáveis e as primeiras ações a serem tomadas no cultivo de uma horta ou qualquer outro cultivo (MELO, 2019, p.121).

O autor relata a prática da coleta e análise do solo e posteriormente sua reposição nutricional. Esta atividade proporcionou o estudo dos elementos químicos e sua relação com a tabela periódica, bem como a fisiologia vegetal nas diferentes composições do solo.

Ao trazer essa temática é proposto mostrar que o solo precisa de correção para o plantio das mais variadas culturas vegetais com objetivo de ter uma maior produção. No cultivo de hortaliças, ter cuidado com o solo é fundamental, o bom ou mau manejo do solo interfere fortemente nos resultados da colheita.

Cada planta tem sua necessidade nutricional e a adição do nutriente ao solo depende de sua disponibilidade no substrato (ERNANI, 2008). Sendo assim, por meio da análise é possível identificar as deficiências e fazer a correção caso seja necessário.

A prática desenvolvida demonstra que a horta escolar é para Ensino de Ciências e Biologia uma atividade contextualizada, oportunizando o aluno a conhecer quimicamente e fisicamente a constituição do substrato. É um contribuinte no estudo dos elementos químicos ali presentes e promove a sensibilização sobre a importância da adubação e correção para eficiente produção agrícola. Favorecendo ainda para o contato dos alunos com uma produção sustentável e que serve de referência para aplicação em suas residências e comunidade (MELO, 2019).

Os Parâmetros Curriculares Nacionais da disciplina Ciência da Natureza enfatiza a necessidade do estudo da composição, origem, fertilidade, erosão e conservação do solo (BRASIL, 1998, pág. 71). Para essa questão o extrato de Santos et al. (2019, p.501), destaca:

[...] no espaço horta cria um ambiente importante para a ação pedagógica, podendo ser um atrativo aos conteúdos ensinados, pois ela proporciona aos alunos e professores saírem da clausura da sala de aula e desafiam a conquistarem novas salas ambientes, onde a curiosidade é aguçada, o interesse se coloca em evidência, os alunos se posicionam como sujeitos que constrói seu conhecimento e o professor se destaca orientando e mediando o processo ensino aprendizagem (SANTOS et al.,2019, p.501).

Os autores salientam que uso da ação ativa proporcionada pela horta escolar, rompe com modelos metodológicos ultrapassados no Ensino de Ciências, baseado no professor como principal detentor do saber e o aluno um receptor passivo. Nesse novo contexto, o aluno passa a ser protagonista no processo educacional e o professor inova ao se apoderar de novas metodologias, que estão além da limitação ao uso do quadro e livro didático, e que podem deixar a aula com mais dinamismo, criatividade, interesse e participação do aluno.

Santos et al. (2019, p.503) e Rodrigues, et al. (2018, p. 224), reconhecem que:

[...] os ganhos motivacionais, pedagógicos, ambiental, nutricional e para pesquisa são muito significativos, além do mais são exigidos pequenos espaços ou até mesmo reutilizando recipientes como: baldes velhos, pneus, garrafas pet, latas, caixas d'água velhas, entre outros (SANTOS, et al., 2019, p.503). Os alunos desenvolvem trabalho na horta e aprendem fundamentos de reciclagem, de agricultura orgânica, técnicas de plantio e cuidado da horta sem o uso de agrotóxicos relacionando assim com o conteúdo recebido em sala de aula no ensino de ciências naturais (RODRIGUES, et al., 2018, p. 224).

Os trechos demonstram a prática da reciclagem e aproveitamento do lixo e sua colaboração social e ambiental no contexto da horta escolar. As ações 
desenvolvidas acabam por reduzir, reaproveitar e reciclar os resíduos sólidos produzido na escola e sociedade local. Os resíduos produzidos podem ser aproveitados na compostagem, construção de canteiros, sementeiras ou até mesmo para ornamentação dos canteiros.

Os artigos de Silva et al. (2011, p. 51) e Benites, et al. (2014, p.44) indicam o uso da horta para trabalhar temas como funções rítmicas, reprodução vegetal e alimentação saudável:

É possível na horta da escola trabalhar com funções rítmicas nos vegetais: a frutificação de algumas plantas e as estações do ano, a abertura e o fechamento de flores ao longo do dia, permitem que se construa a noção de que os vegetais (como todos os seres vivos) apresentem funções que se repetem com o mesmo intervalo de tempo (funções rítmicas), ajustadas ao dia, à noite e às estações do ano (ciclos geofísicos) (SILVA, et al, 2011,p. 51).

[...] possível estudar a participação de insetos e pássaros na polinização, a formação dos frutos, sua variedade, suas condições de germinação, o crescimento das sementes, a influenciada luz, do calor, da água e do ar (SILVA et al., 2011, p. 51).

Essa atividade foi bastante importante, pois foi possível conversar com eles da importância de cuidar da terra, de produzir alimentos de boa qualidade livre de agrotóxicos [...] (BENITES et al., 2014, p.44)

[...] satisfação de poder aproveitar na alimentação escolar as hortaliças que ajudou a cultivar, o aluno aprende o seu valor nutritivo, bem como seus benefícios para a sua saúde (BENITES, et al., 2014, p. 44).

Os autores demonstram a possibilidade do uso da horta para trabalhar com uma variedade de conteúdos práticos e bastante relevantes, que aproximam o aluno da cultura, meio ambiente e de uma vida mais saudável. Neste sentido, é possível diferenciar os ciclos de vida das hortaliças, bem como as relações ecológicas estabelecidas entre as espécies de organismos, além de sensibilizar o aluno para uma alimentação mais saudável e nutritiva, com a caracterização dos nutrientes constituintes dos vegetais, as vitaminas, minerais e fibras (AMARAL 2009; NOGUEIRA, 2006). Souza, et al. (2018, p. 3) sinaliza que:

A escola é o local socialmente definido para a aquisição dos conhecimentos construídos historicamente pela humanidade e nesta perspectiva é fundamental que a escola trabalhe a Educação Ambiental para incentivar a mudança na cultura alimentar dos estudantes, fazendoos além de conhecer a importância dos alimentos, seu valor nutritivo, entenderem toda relação da agricultura e ambiente, estimulando o pensamento crítico para análise dos diversos fatores que estão por traz da produção de alimentos (SOUZA, et al., 2018, p. 3).

O Programa Nacional de Alimentação de Alimentação Escolar (PNAE) considera fundamental implantação de educação alimentar no currículo escolar, no sentido de promover bons hábitos nutritivos e minimizar os danos provocados pelos maus hábitos alimentares (BRASIL, 2009).

O Ensino de Ciências da Natureza precisa estar aliado a real vivência do aluno, com práticas e que proporcionem seu entendimento e aprendizagem. Dentro desta proposta o PCN (1997), espera que o meio ambiente, seus componentes e suas interações sejam estudados de maneira concreta e de forma significativa. Sobre isso o estrato de Rodrigues et al. (2018, p. 228), destaca:

A união horta e sala de aula podem fazer com que o aluno se interesse mais pelas questões que envolvem o meio ambiente, assim como se sentir atraído pelo aprender em forma de pesquisa levando ao questionamento e o despertar cientíco com o auxílio de sistemas naturais bem próximos como a horta na escola (RODRIGUES et al., 2018, p. 228).

Zompero e Laburu (2011) destacam que as aulas com base na investigação favorecem para instigar a participação do aluno em pesquisas científicas e promovem o desenvolvimento de competências, habilidades e assimilação de conteúdos e para revolucionar problemas individuais e coletivos. Desta forma, a horta escolar quando é amplamente acolhida como espaço pedagógico pelo grupo escolar oferece aos alunos uma formação nas múltiplas dimensões e no sentido integral.

O uso da horta também contribui para resgate do conhecimento tradicional. É o que relata Benites et al. (2014, p.42), implantação de uma horta na escola indígena da aldeia Pirajuí, município de Paranhos, MS:

Os indígenas tinham o costume de construir suas casas no meio ou na beira do mato, e no mesmo local fazia sua roça, não precisava ir longe para plantar. As mulheres faziam sua horta em redor de sua casa e plantavam de tudo que tinham conhecimento, como mamão, chicória, cana-de-açúcar, banana, milho, batata doce, mandioca, cará, cebolinha, coentro, manjerona, sendo estes dois últimos considerados remédios na tradição guarani (BENITES et al., 2014, p.42).

O contato de indígenas e não indígena promoveu a incorporação de hábitos alimentares de outros grupos sociais nas comunidades indígenas, e trouxe 
como consequência mudanças no cultivo das plantas. Ao propor práticas com horta, foi possível identificar espécies vegetais que comumente eram plantadas e manejos culturais na horta, específicos da comunidade indígena Guarani. Como destaca:

[...]naquela época não precisava molhar todos os dias a horta, porque tinha muito mato e a umidade ajudava as plantações crescerem. Atualmente só existe campo e quando vai ter horta tem muito trabalho para que as plantas cresçam bem sadias [...] (BENITES, et al, 2014, p. 42)

[...] as plantas mais antigas estão desaparecendo, e a comunidade pegou o costume de plantar as verduras que os não índios plantam como tomate, repolho, alface e couve (BENITES, et al, 2014, p.42).

Cabe destacar que uso da horta escolar como ferramenta pedagógica está dentro do que recomenda a Base Nacional Comum Curricular para o Ensino de Ciências da Natureza, competência 2 e 3 do Ensino Fundamental e competência 1 e 2 para Ensino Médio.

2. Compreender conceitos fundamentais e estruturas explicativas das Ciências da Natureza, bem como dominar processos, práticas e procedimentos da investigação científica, de modo a sentir segurança no debate de questões científicas, tecnológicas, socioambientais e do mundo do trabalho, continuar aprendendo e colaborar para a construção de uma sociedade justa, democrática e inclusiva.

3. Analisar, compreender e explicar características, fenômenos e processos relativos ao mundo natural, social e tecnológico (incluindo o digital), como também as relações que se estabelecem entre eles, exercitando a curiosidade para fazer perguntas, buscar respostas e criar soluções (inclusive tecnológicas) com base nos conhecimentos das Ciências da Natureza (BRASIL, 2017, p.324).

1. Analisar fenômenos naturais e processos tecnológicos, com base nas interações e relações entre matéria e energia, para propor ações individuais e coletivas que aperfeiçoem processos produtivos, minimizem impactos socioambientais e melhorem as condições de vida em âmbito local, regional e global.

2. Analisar e utilizar interpretações sobre a dinâmica da Vida, da Terra e do Cosmos para elaborar argumentos, realizar previsões sobre o funcionamento e a evolução dos seres vivos e do Universo, e fundamentar e defender decisões éticas e responsáveis (BRASIL, 2017, p.253).

A partir desse contexto legal é possível inferir que a horta escolar pode ser utilizada como espaço privilegiado nas práticas pedagógicas sustentáveis. Estas trazem inúmeras possibilidades dentro do ambiente escolar, com garantia aos educandos de compreender conceitos e práticas com uso constante da investigação ambiental para entendimento da dinâmica da vida no planeta e suas interações com fatores abióticos, fortalecendo debates questões científicas e socioambientais.

As políticas públicas garantem a inclusão de pessoas com Necessidades Educacionais Especiais (NEE) no sistema regular de ensino, portanto, escolas e professores devem estar preparados a receber este público e educá-los de forma integral para o pleno exercício da cidadania. Para aulas de Ciências e Biologia o uso de metodologias com horta escolar pode ser uma ótima alternativa para que isso aconteça de forma efetiva.

São estimados cerca 712 mil matrículas em escolas regulares e escolas especiais, e este fato contribui para minimizar exclusão deste público e lhes garantir o pleno direito a educação de qualidade e desenvolvimento de habilidades e competências que contribuirão em tomadas de decisões para um bom projeto de vida (NUNES, 2016).

NUNES (2016) ao trabalhar com horta escolar em uma organização de sociedade civil sem fins lucrativos, Associação de Pais e Amigos dos Excepcionais (APAE), sinaliza que:

Durante as atividades na horta os alunos eram instigados a questionarem sobre os fenômenos naturais observados e suas interações eram divididas em categorias, quais sejam: conceitos, procedimentos e atitudes (NUNES, 2016, p. 14).

[...]os alunos começaram a participar efetivamente do cultivo da horta. Desse modo, conteúdos procedimentais, tais como, observação, interpretação das informações e expressão oral, bem como, atividades motoras, foram desenvolvidos (NUNES, 2016, p.15).

Enfatiza a relevante contribuição para estes alunos na promoção hábitos alimentares saudáveis, aproximação do saber cientifico e cumprimento de uma educação integral que é assegurado a este público desde a constituição de 1988.

Ao desenvolver esta atividade temas específicos da Ciência da Natureza como resíduos sólidos, ciclo de vida das plantas, fatores abióticos e bióticos, fisiologia vegetal e preservação se tornaram mais próximos da realidade desses alunos e muito contribuiu na formação de aprendizagens práticas de ciências e para uma efetiva Educação Ambiental e aprendizagens significativas (RAMOS, 2013). Segundo 
Nunes (2016), foi possível apreensão de conteúdos procedimentais como observação, análise e comparação, identificados em questionamentos e cooperações coletivas dos estudantes.

Tanto Silveira (2015) como Oliveira (2017) ressaltam que a práticas com horta aproxima os alunos e professores, resgatando importância do trabalho em equipe e cooperação entre os envolvidos, bem como, discutir temas relacionados a tecnologia, emprego e renda. Como destacam:

A questão pedagógica, não é apenas a questão da aprendizagem, mas também a dos valores fundadores da ação: humanismo, respeito aos outros, democracia, trocas e solidariedade (SILVEIRA, 2015, p. 4).

Os instrumentos de trabalho na agricultura e as técnicas de plantio permitem pensar sobre tecnologia e as condições sociais de trabalho e emprego. A modificação de um espaço para a implantação de uma horta favorece as discussões sobre a divisão da terra e a ação do homem na degradação ambiental, saturação dos solos e a exploração desmedida dos recursos (OLIVEIRA, 2017, p.3).

O Uso da horta escolar traz como foco as práticas agrícolas e nos faz refletir sobre as ações antrópicas sobre o ambiente, sendo eficiente na promoção de debates promotores de Educação Ambiental. Desta forma sensibiliza e oportuniza na formação individual e coletiva para a reflexão e construção de atitudes ambientais para a vivência da sustentabilidade. Siqueira et al. (2016) destaca:

O tema Educação Ambiental, que deveria aparecer de forma transversal em todas as disciplinas do currículo escolar, acaba ficando relegado ao ensino das Ciências por uma questão de tradição cultural (SIQUEIRA et al., 2016, p.5).

A Educação Ambiental é um dos temas mais importantes a serem absorvidos pelas crianças, analisar sua relação com a natureza e os impactos que suas ações podem causar no sentido ecológico. É aí que os projetos de horta escolar se inserem, eles aproximam os estudantes da realidade, fazendo com que as crianças criem hábitos sustentáveis e ecologicamente corretos (SIQUEIRA et al., 2016, p.4).

A Política Nacional de Educação Ambiental artigo $1^{\circ}$ da lei $9.795 / 99$ propõe que:

Entendem-se por educação ambiental os processos por meio dos quais o indivíduo e a coletividade constroem valores sociais, conhecimentos, habilidades, atitudes e competências voltadas para a conservação do meio ambiente, bem de uso comum do povo, essencial à sadia qualidade de vida e sua sustentabilidade.
O cenário global de mudanças climáticas, degradação, redução da biodiversidade, riscos socioambientais locais e globais exigem atitudes e rupturas imediatas com esse modelo de consumo insustentável, e as escolas precisam incluir a Educação ambiental para intervir, como propõe as Leis de Diretrizes e Bases da Educação (Lei $\mathrm{n}^{\circ}$ 9.394/1996) e Diretrizes Curriculares Nacionais de Educação Ambiental, estabelecidas pela Resolução $\mathrm{n}^{\circ} 2$, de 15 de junho de 2012, do Conselho Nacional de Educação.

\section{CONSIDERAÇÕES FINAIS}

A partir da análise dos artigos há indicadores que o uso horta escolar contribui como uma ótima ferramenta na prática pedagógica para o Ensino de Biologia e Ciências, uma vez que possibilita o desenvolvimento de aulas práticas que dialogam com o conteúdo teórico das disciplinas, tornando esse momento de aprendizagem mais dinâmico, contextualizado e favorecendo para eficiente Educação Ambiental.

Desta forma, torna possível o cumprimento do que preconiza a lei de Política Nacional de Educação Ambiental, artigo 9.795/99, a Lei de Diretrizes e Bases da Educação (Lei n 9.394/1996) e as Diretrizes Curriculares Nacionais de Educação Ambiental, estabelecidas pela Resolução $\mathrm{n}^{\circ} 2$, de 15 de junho de 2012, do Conselho Nacional de Educação. A inserção da horta escolar nas práticas de Ensino de Biologia e Ciências promovem reflexões para desenvolvimento de saberes necessários à educação ambiental crítica, de resgate cultural, inclusiva e transformadora.

Além disso, o uso da horta possibilita reunir diferentes áreas do conhecimento na adoção de práticas para vivência na sustentabilidade ambiental, aproximando toda a comunidade escolar de saberes que colaboram para preservar, reduzir, reutilizar e reciclar.

\section{REFERÊNCIAS}

AGUIAR, P.C.B.; NETO, R. F. C.; B. N. L.; PROFICE, C. C. Da Teoria À Prática Em Educação Ambiental. Revista Gestão \& Sustentabilidade Ambiental. Florianópolis, v. 6, n. 3, 2017. Disponível em: file:///C:/Users/Ceep/Downloads/5154-12651-1SM.pdf. Acesso em: 28 nov. 2020. 
ANDRADE, Julia P.; SARTORI, Juliana. O professor autor e experiências significativas na educação do século XXI: estratégias ativas baseada na metodologia de contextualização da aprendizagem. In: BACICH, Lilian. MORAN, José (Orgs.). Metodologias ativas para uma educação inovadora: uma abordagem teórico-prática [recurso eletrônico]. Porto Alegre: Penso, 2018. cap. 8, ePUB.

AMARAL, A. Q.; JUNIOR, E. J. H.; SADRAQUE, C.; MIGUEL, K.; LARA, J. G. A implantação de horta orgânica como instrumento para a formação de alunos participativos. Seminário Internacional "Experiências de Agendas 21: Os desafios do nosso tempo". Ponta Grossa, 2009.

BANDEIRA, D.P.; Práticas Sustentáveis na Educação: interdisciplinaridade através do Projeto Horta Escolar. Revista de Educação do Cogeime. Ano 22. n.43, 2013.2 Disponível em: $<$ www.redemetodista.edu. br/revistas/revistascogeime>. Acesso em: 30 de nov.2020.

BRASIL. Ministério da Educação. Base Nacional Comum Curricular. MEC, 2017. Brasília: 2017. Disponível

em: http://basenacionalcomum.mec.gov.br/images/BN CC_20dez_site.pdf. Acesso em: 11 de junho de 2020.

BRASIL. Ministério da Educação. Secretaria de Educação Média e Tecnológica. Parâmetros Curriculares Nacionais: Ensino Médio. Brasília: Ministério da Educação, 2002.

BRASIL. Secretaria de Educação Fundamental. Parâmetros Curriculares Nacionais: $3^{\circ}$ e $4^{\circ}$ ciclos do ensino fundamental; Ciências Naturais. Secretaria de Educação Fundamental. Brasília: MEC/SEC, 1998. $138 \mathrm{p}$.

BRASIL. Secretaria de Educação Fundamental. Parâmetros Curriculares Nacionais: Ciências Naturais / Secretaria de Educação Fundamental. Brasília: MEC/SEF, 1997. $136 \mathrm{p}$.

BRASIL. Secretaria de Educação Fundamental. Parâmetros Curriculares Nacionais para o Ensino Fundamental. Brasília: MEC/SEF, 1997. 126 p.

ERNANI, P. R. Química do Solo e disponibilidade de nutrientes. Paulo Roberto Ernani-Lages: O Autor, 2008.
FROES, E. H.; PEZENTI, M.; KRUG, A. L.; MILANO, M. Z.; PEDROZA, F. A. Hortas escolares: uma proposta de integração da horta às disciplinas do ensino fundamental nas escolas do alto vale do Itajaí. In: MOSTRA NACIONAL DE INICIAÇÃO CIENTÍFICA E TECNOLOGIA INTERDISCIPLINAR, 8.2015. Santa Rosa. Anais [...]. Santa Rosa do Sul: Campus IFC. 2015.

Disponível em: http://eventos.ifc.edu.br/wpcontent/uploads/sites/5/2015/10/HORTAS-

ESCOLARES-UMA-PROPOSTA-DE-

INTEGRA\%C3\%87\%C3\%830-DA-HORTA-\%C3\%80S-

DISCIPLINAS-DO-ENSINO-FUNDAMENTAL-NAS-

ESCOLAS-DO-ALTO-VALE-DO-ITAJA\%C3\%8D.pdf.

Acesso em: 16 jan. 2020.

GUARIM, V. L. M. S. Barranco Alto: Uma experiência em Educação Ambiental. Cuiabá: UFMT, 2002.

MARINHO, A. M. L.; SANTOS, A. C.; MINEIRO, A. E. S.; LIMA, J. D. C. C.; FERREIRA, M. R.; LIMA, R.; MOREIRA, S. L. M. A educação através de espaços não formais de ensino de ciências em Teresina - PI. In: ENCONTRO NACIONAL DE ENSINO DE BIOLOGIA, 4, 2012. Anais [...] Goiânia: IV ENEBIO e II EREBIO, Regional 4, p. 01 - 08.2002. Disponível em: https://sbenbio.org.br/wp

content/uploads/edicoes/revista_sbenbio_n5/arqui vos/4307.pdf Acesso em: 15 mar.2020.

MELO, J. S. Horta escolar, cultivar é educar. Revista Insignare. V.2, n. 1, ano 2019.

Disponível em: https://periodicos.uffs.edu.br/index.php/RIS/articl e/view/10776. Acesso em: 15 mar.2020.

MORAES, R.; GALIAZZI, M. do C. Análise Textual Discursiva: processo reconstrutivo de múltiplas faces. Ciência \& Educação, Bauru, v. 12, n. 1, p. 117-128, 2006. Disponível em: https://www.scielo.br/pdf/ciedu/v12n1/08.pdf. Acesso em: 15 mai.2020.

NOGUEIRA, W.C.L. Horta na escola - "Uma alternativa de Melhoria na Alimentação e Qualidade de vida". In: ENCONTRO DE ENSINO PESQUISA E EXTESÃO., 10.2016. Anais [...] Minas Gerais:ENEPEX. Minas Gerais, 2016. Disponível em: file:///C:/Users/Ceep/Downloads/3988-7271-1PB\%20(1). Pdf. Acesso em: 15 mai.2019. 
NUNES, C. de B.; DIAMANTINO, F. K. de L.; GONÇALVES, T. V. O. A prática experimental como instrumento didático para uma nova visão da ciência do ponto de vista do alunado. In: ENCONTRO NACIONAL DE ENSINO DE BIOLOGIA, 3, 2010, Fortaleza. Anais [...] Fortaleza: III ENEBIO \& IV EREBIO - Regional $5 \mathrm{~V}$, Congreso Iberoamericano de Educación en Ciências Experimentales Revista da SBEnBio - Número 03. 2010, p. 2124 - 2132.

PEREIRA, B. F. P.; PEREIRA, M. B. P.; PEREIRA, F. A. A. Enriquecendo o ambiente estudantil Distrito de Mosqueiro-Belém/PA. Revista Brasileira de Educação. v.,7, n. 1, 2012.Disponível em:https://periodicos.unifesp.br/index.php/revbe a/article/view/1739/1176 Acesso em: 20 mai.2020.

RAMOS, D.K. A aprendizagem colaborativa e a educação problematizadora para um enfoqueglobalizador. Cadernos da Pedagogia. São Carlos, Ano 6, v.6, n.12, p. 105-115, jan- jun. 2013. Disponível em: http://www.cadernosdapedagogia.ufscar.br/index. $\mathrm{php} / \mathrm{cp} /$ article/viewFile/506/207. Acesso em: 28 nov. 2020.

SASSI, J, S; LINDEMANN, R. H. Horta escolar: reflexões a partir de pesquisas da área de Ensino de Ciências e Biologia. In: IX ENCONTRO NACIONAL DE
PESQUISA EM EDUCAÇÃO EM CIÊNCIAS, 4, 2013, Águas de Lindóia. Anais [...] Águas de Lindóia: IX ENPEC, 2013. Disponível em: http://www.nutes.ufrj.br/abrapec/ixenpec/atas/r esumos/R1093-1.pdf.Acesso em: 02 Maio. 2020.

SALGADO, G. N.; PERES, P. M. S. "Fazer ou não uma horta escolar?" Um modelo de curso de formação de educadores que dá cinco razões para se fazer uma horta pedagógica. In: ENCONTRO NACIONAL DE ENSINO DE BIOLOGIA, 3, 2010, Fortaleza. Anais [...] Fortaleza: III ENEBIO \& IV EREBIO - Regional 5 V, Congreso Iberoamericano de Educación en Ciências Experimentales Revista da SBEnBio - Número 03. 2010.p. 1311 - 1320.

SILVA, F. O; ANJOS, M. B.; CRIBB, S. L. S. P. Hortas orgânicas: uma proposta para políticas públicas na educação. In: ENCONTRO NACIONAL DE PESQUISA EM EDUCAÇÃO EM CIÊNCIAS, 4, Valinhos: VI ENPEC, 2007. Anais [...] Águas de Lindóia: VI ENPEC, 2007. p. 1 - 12.

ZOMPERO, A. F.; LABURU, C. E. Atividades investigativas no ensino de ciências:

aspectos históricos e diferentes abordagens. Revista Ensaio, Belo Horizonte, v.13, n.3, p. 67-80, $2011 . \quad$ Disponível em: https: / /www.scielo.br/pdf/epec/v13n3/1983-2117epec-13-03-00067.pdf. Acesso: 10 set. 2020. 